\title{
Global Citizenship Education in the English Language Classroom: Theory and Practice
}

\author{
Elizabeth Jeanne Norman ${ }^{1, *}$
}

\author{
${ }^{1}$ Gyeonggi-do Institute For Language Education \\ *Email: Elizabeth.gifle@gmail.com
}

\begin{abstract}
The field of Global Citizenship Education (GCE) has gained momentum in the last few decades. Even as researchers continue to develop the definition of the concept, GCE has found its place in the curriculum and education policy of many countries, notably in South Korea. Recently, studies have shown that the English Language classroom is an optimal place for integrating GCE themes and objectives. In response, in-service training programs like the one at the Gyeonggi-do Institute For Language Education have begun implementing modules on GCE, and the results show that even one training module can lead to the successful integration of GCE by Secondary English language Teachers. These results showcase a need for more GCE programs to adequately prepare educators for reaching GCE related educational standards.
\end{abstract}

\section{Keywords: Global Citizenship Education, Teacher Education, global citizen}

\section{INTRODUCTION}

In 2015, UN member-states met to discuss the future of education for the next fifteen years. One of the products of that meeting was an implementation of Global Citizenship Education (GCE) into global education policy [1]. GCE was integrated into education policy and curriculum as a response to the need for the students of today to be aware of their place in the increasingly interconnected global landscape [2]. The United Nations Educational, Scientific, and Cultural Organization (UNESCO) defined the concept of GCE as a "framing paradigm which encapsulates how education can develop the knowledge, skills, values, and attitudes learners need for securing a world which is more just, peaceful, tolerant, inclusive, secure, and sustainable" [3]. In response, GCE was integrated into curriculum and policy for many of the ratifying countries, but South Korea, in particular, pushed for the concept to be present in the social studies and ethics classroom [4],[18]. In the last two decades, GCE has developed into an established field of study, with scholars looking at the concept from a variety of different perspectives and lenses [5]. As scholars have researched the optimal spaces for GCE curriculum, it has become clear that the social studies and ethics classroom are not the only subjects in which GCE can be integrated [6],[4]. Contemporary research suggests that the themes and objectives of GCE may be effective in the English as a Foreign Language classroom [7].

\subsection{GCE Themes}

The themes and objectives related to GCE vary depending on the "type" of GCE and the lens through which it is being portrayed [5]. Such as the neoliberal approach, which looks at GCE from an economic standpoint, helping students to participate in the global economy [8]. "Soft GCE" portrays GCE as the process by which learners seek to understand global issues and participate in a globalizing culture [9]. Both perspectives have been criticized for their west-centric point of view and unrealistic attitude towards global issues [10],[11]. "Critical GCE" encourages educators to guide learners to critically assess the topics and issues presented within the GCE curriculum. Often referred to as "transformative," Critical GCE puts emphasis on action as opposed to surface-level understanding [11].

With the variety of literature available on GCE, it can be difficult for scholars and educators to agree on the central themes [1]. However, one of the most notable sources related to GCE, the Online GCED Campus, has settled on five main themes that can be 
found in most GCE literature and curriculum [12]. These five themes are

1. Human Rights Education- Understanding what a human right is and how human rights might be in danger or protected in one's local community and abroad.

2. Conflict and Peace Building- Critically looking at both sides of global issues and how those issues might be resolved peacefully.

3. Respect for Diversity- Developing a transformative awareness of and respect for diversity as well as taking action on diversity issues on the local and global stage.

4. Globalization and Social Justice- Looking at country interdependence and power disparities in globalization along with the concept of social justice, which promotes the understanding that individuals deserve equal economic, political, and social rights and opportunities.

5. Sustainability- The view that Earth has limited resources and humanity must learn how to actively work to keep these resources sustainable for future generations.

\section{GCE IN EFL}

The themes and concepts related to GCE have been steadily finding their way into the English as a Foreign Language (EFL) and English as a Second Language (ESL) classrooms over the last few years [13]. Studies have shown that the EFL/ESL is an "optimal space for GCE" [7]. There are several reasons why researchers are starting to lean on the EFL/ESL classroom as a place for implementing GCE themes and objectives. The first reason is that GCE helps learners to develop global identity. By identifying themselves as global citizens, learners start to view English as a way to communicate with fellow citizens in the global landscape rather than a means to access the Englishspeaking world or participate in western culture [14]. Another reason GCE is successful in the EFL/ESL classroom is that the English language curriculum often already encompasses many of the themes related to GCE. Such as respecting diversity and culture, innovation and technology related to sustainability, and seeking to understand and combat global issues [7]. Finally, looking at GCE from an educator's standpoint, English language teachers often have more resources and opportunities for global training, which helps when tasked with implanting GCE into their subject, which is why in-service training programs for
English language teachers in South Korea are starting to include GCE as a training module.

\section{GCE AND TEACHER EDUCATION}

Despite the attention paid to GCE by policymakers and curriculum developers, GCE remains a tertiary subject in the field of teacher education [15]. In the case of South Korea, resources and curriculum have been made available [16],[19], but without proper training, educators still feel inadequately prepared for integrating the concept of GCE into their lessons [17]. This is especially true for English language educators, who have only been expected to implement GCE objectives recently. To combat this, Secondary English as a Foreign Language teachers were given the opportunity to watch a 20-minute video on GCE and the GCE themes outlined in this article as a part of an in-service training operated by the Gyeonggi-do Institute For Language Education in Gyeonggi-do, South Korea. After watching the video, educators were asked to implement one or more of the themes into a lesson and present the lesson overview, results, and reflection to their fellow educators during the training program. The following are a few examples of lessons produced after just 20 minutes of training on GCE and the GCE themes.

\subsection{UNESCOS SDGs as a Video-making Assignment (PSA)}

Trainee A decided to take on a broader look at GCE and guided a mixed-level class of $281^{\text {st }}$ grade high school students to design and produce a video based on one of the UNESCO Sustainable Development Goals (SDG). Trainee A started by outlining the concept of GCE along with samples of public service announcements (PSA) on a variety of topics. Students were then directed to form groups and choose one of the SDGs as their topic. The videos were created over the course of several lessons, with the end products presented as a part of a mini-film festival on the last day of the special unit. In the reflection portion of their presentation, Trainee A mentioned the engagement of students in the class and the ease with which they were able to connect the concept of the SDGs to their own daily lives.

\subsection{Social Justice and the BLM Campaign}

Trainee B took a more detailed approach to develop a sample lesson and chose to focus on the GCE theme of social justice and globalization. For their high school $2^{\text {nd }}$ year students, they developed a 
lesson centered on racism and the impact of the Black Lives Matter campaign (BLM). Trainee B eased students into the lesson by showing an example of racism in media and challenging students to answer questions such as "What is the purpose of this ad?" and "How do you feel after watching this ad?". Trainee B then segued into showing pictures related to BLM and asking students to connect the global issue with their own lives. The lesson ended with Trainee B asking students to come up with a plan for action on how they can combat racism online and in their own daily lives.

\subsection{GCE and Diversity Education}

Trainee $\mathrm{C}$ chose to focus on the GCE theme of respect for diversity. For their high school students, they first outlined the concept of GCE as well as the importance of understanding others. Students were then shown the TEDtalk titled "The Danger of a Single Story" by Chimamanda Ngozi Adichie. After watching the video and answering the knowledge checks, students were tasked with connecting the concept of prejudice as presented by Adichie with the GCE theme of respect for understanding. The lesson finished with Trainee C motivating students to engage in their EFL subject as a way to deepen their understanding of others and respect global diversity.

\section{CONCLUSION}

The field of Global Citizenship Education is still being developed; scholars are criticizing and overturning concepts faster than educators can produce a curriculum. However, the central themes of GCE have found a place in the English language classroom in several countries, most recently in South Korea. As shown by the results of the module presented at the Gyeonggi-do Institute For Language Education, pre-service and in-service training programs are needed to equip educators with the knowledge and skills order to reach GCE-related educational standards and objectives.

\section{ACKNOWLEDGMENTS}

Thank you to the teachers who participated in the in-service training program at the Gyeonggi-do Institute For Language Education and gave permission for their lessons and materials to be used as examples in this article.

\section{REFERENCES}

[1] W. Gaudelli, Global citizenship education: everyday transcendence. London: Routledge, 2016.

[2] I. Davies, L.-C. Ho, D. Kiwan, C. L. Peck, A. Peterson, E. Sant, and Y. Waghid, Palgrave handbook of global citizenship and education. London: Palgrave Macmillan, 2018.

[3] M. J. Pigozzi, “A UNESCO view of global citizenship education," Educational Review, vol. 58, no. 1, pp. 1-4, 2006. DOI: $10.1080 / 00131910500352473$

[4] J.-E. Noh, "Global Citizenship Education in South Korea: The Roles of NGOs in Cultivating Global Citizens," The Palgrave Handbook of Citizenship and Education, pp. 359-374, 2020. DOI: 10.1007/978-3-319-67828-3_13

[5] L. Shultz, "Educating for Global Citizenship: Conflicting Agendas and Understandings," Ajer Online, vol. 53, no. 3, pp. 248-258, 2007. DOI: https://doi.org/10.11575/ajer.v53i3.55291

[6] K. Kang and J. H. Oh, "Outcomes of global citizenship education for Korean students.," Secondary Education Research, vol. 63, no. 1, pp. 1'-32, 2015.

[7] M. Lourenço and A. R. Simões, "Teaching and Learning for Global Citizenship in the EFL Classroom," Teaching and Learning Practices That Promote Sustainable Development and Active Citizenship Advances in Educational Technologies and Instructional Design, pp. 86106, 2021. DOI: 10.4018/978-1-7998-4402$0 . \operatorname{ch} 005$

[8] H. S. Cho and J. Mosselson, "Neoliberal practices amidst social justice orientations: global citizenship education in South Korea," Compare: A Journal of Comparative and International Education, vol. 48, no. 6, pp. 861-878, 2017. DOI: doi:10.1080/03057925.2017.1364154

[9] W. Veugelers, "The moral and the political in global citizenship: appreciating differences in education," Globalisation, Societies and Education, vol. 9, no. 3-4, pp. 473-485, 2011. DOI: $10.1080 / 14767724.2011 .605329$

[10] H. S. Cho, "Issues and challenges of educators in implementing global citizenship education in South Korea," KEDI Journal of Educational Policy, vol. 14, no. 2, 2017. 
[11] A. Pais and M. Costa, "An ideology critique of global citizenship education," Critical Studies in Education, vol. 61, no. 1, pp. 1-16, 2017. DOI: 10.1080/17508487.2017.1318772

[12] GCED Online Campus. [Online]. Available: http://www.gcedonlinecampus.org/. [Accessed: 14-Oct-2021].

[13] A. R. Chirciu, "Global Citizenship in the English Language Classroom: Student Readiness for Critical Reform," Critical Issues in Teaching English and Language Education, pp. 123-151, 2020. DOI: https://doi.org/10.1007/978-3-03053297-0_6

[14] K. Sumaryono and F. Ortiz, "Preserving the Cultural Identity of the English Language Learner," Voices from the Middle, vol. 11, no. 4, pp. 16-19, May 2004.

[15] E. Saperstein, "Global Citizenship Education Starts With Teacher Training and Professional Development," Journal of Global Education and Research, vol. 4, no. 2, pp. 125-139, Dec. 2020. DOI: $\quad$ https://www.doi.org/10.5038/2577509X.4.2.1121

[16] S.-Y. Pak, "From Global Competitiveness to Global Citizen: The Case of South Korea's GCED Lead Teacher Program," in Research of Global Citizenship Education in Asia, Charlotte, NC: Information Age Publishing, 2021, pp. 183-205.

[17] Y. Kim, "Global citizenship education in South Korea: ideologies, inequalities, and teacher voices," Globalisation, Societies and Education, vol. 17, no. 2, pp. 177-193, $2019 . \quad$ DOI: https://doi.org/10.1080/14767724.2019.1642182

[18] R. J. Moon and J.-W. Koo, “Global Citizenship and Human Rights: A Longitudinal Analysis of Social Studies and Ethics Textbooks in the Republic of Korea," Comparative Education Review, vol. 55, no. 4, pp. 574-599, 2011. DOI: doi: $10.1086 / 660796$

[19] M. Estellés and G. E. Fischman, "Who Needs Global Citizenship Education? A Review of the Literature on Teacher Education," Journal of Teacher Education, vol. 72, no. 2, pp. 223-236, 2020.

DOI:

https://doi.org/10.1177/0022487120920254 